Original article

\title{
Linkages between the soil organic matter fractions and the microbial metabolic functional diversity within a broad-leaved Korean pine forest
}

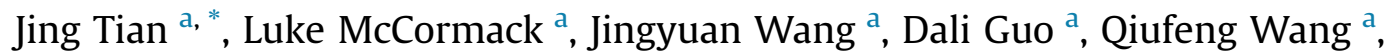 \\ Xinyu Zhang a , Guirui Yu ${ }^{\text {a, * }}$, Evgenia Blagodatskaya ${ }^{\text {b }}$, Yakov Kuzyakov ${ }^{\text {b, c }}$ \\ ${ }^{a}$ Key Laboratory of Ecosystem Network Observation and Modeling, Institute of Geographic Sciences and Natural Resources Research, Chinese Academy of \\ Sciences (CAS), 100101 Beijing, China \\ ${ }^{\mathrm{b}}$ Department of Soil Science of Temperate Ecosystems, University of Göttingen, 37077 Göttingen, Germany

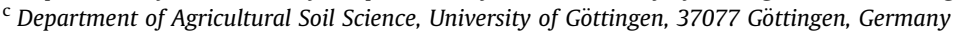

\section{A R T I C L E I N F O}

\section{Article history:}

Received 23 July 2014

Received in revised form

25 November 2014

Accepted 5 December 2014

Available online 7 December 2014

Handling editor: Bryan Griffiths

\section{Keywords:}

Spatial distribution

Functional diversity

Soil organic matter fractions

Forest ecosystem

Soil microorganisms

\begin{abstract}
A B S T R A C T
Patterns in the spatial distribution of soil microorganisms and the factors that determine them provide important information about the mechanisms regulating diversity and function of terrestrial ecosystems. The spatial heterogeneity of metabolic functional diversity of soil microorganisms was studied across a $30 \times 40 \mathrm{~m}$ plot and at two soil depths $(0-10 \mathrm{~cm}$ and $10-20 \mathrm{~cm})$ in a natural, mixed broad-leaved Korean pine (Pinus koraiensis) forest soil in the Changbai Mountains. In addition, we assessed the importance of the quantity and quality (indicated by labile soil organic matter fractions) of soil organic matter in smallscale structuring of soil microbial metabolic functional diversity. Microbial metabolic functional diversity was characterized based on the Biolog profile. The results showed that metabolic activity exhibited moderate spatial dependence, while functional diversity had a much stronger spatial dependence. All soil organic matter fractions including total soil organic matter, dissolved organic matter, particulate organic matter explained $15-27 \%$ of the variance in microbial functional diversity in the two soil layers. Among all soil organic matter fractions, the labile dissolved organic carbon accounted for the largest amount of variation. Overall, the significant relationship between soil microorganisms and organic matter fractions allows for better understanding the ecological functions governing $\mathrm{C}$ cycling and microbial communities in forest ecosystems.
\end{abstract}

(c) 2014 Elsevier Masson SAS. All rights reserved.

\section{Introduction}

Soil microorganisms are important components of terrestrial ecosystems and mediate many ecological processes including carbon (C) and nutrient cycling [1], C sequestration [2,3], litter decomposition and primary productivity [4]. Due to high soil heterogeneity, the spatial distribution of microbial metabolic activity is a key to understand functional variability of soil microhabitats [5]. In addition, information regarding the spatial variability of soil microbial metabolic diversity, and the factors that determine these patterns could lead to more accurate predictions of microbial properties and functions. This in turn would provide important

\footnotetext{
* Corresponding authors.

E-mail addresses: tianj@igsnrr.ac.cn (J. Tian), yugr@igsnrr.ac.cn (G. Yu).
}

information regarding mechanisms that regulate ecosystem function, including $C$ and nutrient cycling $[5,6]$.

Spatial heterogeneity of soil microbial community structure (e.g. fungal-to-bacterial ratio) and activity (e.g. enzyme activity) can occur at small (e.g., $<10 \mathrm{~m}$ ), local and regional scales [7-9]. However, there is little information regarding the spatial variability of microbial metabolic functional diversity in natural forest ecosystems. Abiotic and biotic factors (such as soil moisture, $\mathrm{pH}$ and plant species) play a key role in explaining the spatial variability of microbial communities and activities across a variety of spatial scales [10-13]. For example, plant diversity partially controls microbial diversity and community structure $[10,14]$. The diversity and richness of soil bacterial communities at continental scales have been largely explained by soil pH [11]. However, most of these studies of spatial structure of soil microbial communities focused on the effects of aboveground vegetation, and soil properties such as 
moisture, $\mathrm{pH}$, and texture. Few studies have investigated the relative importance of belowground substrate resources (e.g., soil organic matter, root biomass) in structuring soil communities [15-17]. These data are particularly lacking in regards to the functional diversity of soil communities $[18,19]$. Working at a regional scale, Liu et al. [19] demonstrated that root biomass and soil N:P ratio strongly affected microbial diversity. However, the factors influencing soil microorganisms often differ across a gradient of spatial scales $[5,20]$. Therefore, information on estimating the relative importance of belowground substrate resources in the small-scale structuring of soil microbial metabolic functional diversity is not well understood.

Soil organic matter is a heterogeneous mixture that contains numerous compounds with varying levels of degradability and turnover rates [21]. Labile SOM fractions such as dissolved organic carbon (DOC), dissolved organic nitrogen (DON), particulate organic carbon (POC) and particulate organic nitrogen (PON) are the primary energy source for microorganisms and are characterized by rapid turnover. Further, these labile SOM fractions are thought to be related to the quality of SOM [22,23]. A number of studies have linked SOC, as well as other fractions such as DOC, to soil microbial community structure and activity [24-27]. The catabolic diversity of soil microorganisms was reduced by the decrease of SOC content [28]. In addition, bacterial biomass has also been related to small-scale spatial variations in sediment POC [29]. Natural forest ecosystems generally have heterogeneous distribution of aboveground vegetation [30] and root biomass belowground $[31,32]$. The heterogeneous nature of plant biomass in these ecosystems may create local patchiness of belowground total and labile SOM (e.g., through the quality and quantity of litter inputs and root exudates releases). Presumably, these total and labile SOM sources are key factors that may help explain the spatial heterogeneity of soil microbial functional diversity.

In the current study, we hypothesized that microbial functional diversity is patchily distributed at the small-scale in soil, and the heterogeneity in soil microbial functional diversity is correlated to the SOM source, and particularly to labile SOM hotspots. To test our hypotheses, the spatial variability of soil microbial functional diversity and belowground SOM source were studied in a mixed broad-leaved Korean pine (Pinus koraiensis) forest in a $30 \times 40 \mathrm{~m}$ plot at 2 soil depths $(0-10 \mathrm{~cm}$ and $10-20 \mathrm{~cm})$ in the Changbai Mountains, China. We specifically (1) determined the spatial heterogeneity of soil microbial metabolic functional diversity, and (2) assessed the relative importance of the quantity and quality (labile SOM fractions) of organic substrates in the small-scale structuring of soil microbial metabolic functional diversity.

\section{Materials and methods}

\subsection{Site description and sample collection}

The soil sampling was conducted in a long-term plot at the Forest Ecosystem Open Research Station of Changbai Mountains in northeast China in August $2013\left(128^{\circ} 28^{\prime} \mathrm{E}, 42^{\circ} 24^{\prime} \mathrm{N}\right)$. The site is covered by a multi-storied, uneven-aged, multi-species forest that has been relatively undisturbed for ca. 200 years. The area is dominated by Korean pine (P. koraiensis), Tilia amurensis, Acer mono, Fraxinus mandshurica and Quercus mongolica along with 135 other species [33]. The climate for this region is characterized as temperate monsoon with a mean annual temperature of $2.0^{\circ} \mathrm{C}$ and an annual precipitation of $700 \mathrm{~mm}$. The soil is dark brown forest soil originating from volcanic ash, and it is classified as a Haplic Luvisol.

Within the long-term plot, a $30 \times 40 \mathrm{~m}$ sub-plot was established on a relatively flat and homogeneous portion of the study site. The sampling scheme was based on a Latin hypercube design [34], and a total of 51 sampling points were collected (Fig. 1). This design provided a range of separation distances between any two sampling points with the minimum distance being $0.49 \mathrm{~m}$ and the maximum being $44 \mathrm{~m}$. Each point was sampled using a $10 \mathrm{~cm}$ diameter soil corer to a depth of $20 \mathrm{~cm}$.

Following the collection of soil cores, the samples were immediately separated into the $0-10 \mathrm{~cm}$ and $10-20 \mathrm{~cm}$ depth increments. These samples were then stored in airtight polypropylene bags, placed in a cooler box at $\sim 4{ }^{\circ} \mathrm{C}$ and transported to the laboratory. Once in the lab, roots and rock fragments were carefully removed and the remaining soil samples were divided into several subsamples. The subsamples for soil microbial functional diversity and dissolved organic matter concentration analysis were stored at $4{ }^{\circ} \mathrm{C}$. Those for soil organic matter and particulate organic matter were air dried at room temperature.

\subsection{Soil microbial functional diversity analyses}

The soil microbial functional diversity was characterized using the Biolog System [35]. This method has been widely used in determining soil microbial community functional diversity under various conditions [36-38]. 31C substrates associated with plant root exudates were used in the Eco-plate. We divided them into six groups according to Preston-Mafham et al. [39]: seven carbohydrates ( $\beta$-Methyl-D-glucoside, D-Xylose, i-Erythritol, d-Mannitol, NAcetyl-D-galactosamine, D-Cellobiose and $\alpha$-D-Lactose), six amino acids (L-Arginine, L-Asparagine, L-Phenylalanine, L-Serine, L-Threonine, and Glycyl-L-glutamic acid), nine carboxylic acids (D-Galactonic acid $\Upsilon$-lactone, D-Galacturonic acid, 2-Hydroxy benzoic acid, 4-Hydroxy benzoic acid, $\Upsilon$-Hydroxy butyric acid, Itaconic acid, $\alpha$ Keto butyric acid, D-Glucosaminic acid and D-Malic acid), two amines (Phenylethylamine and Putrescine), four polymers (Tween 40, Tween 80, $\alpha$-Cyclodextrin and Glycogen), and three miscellaneous (Pyruvic acid methy 1 ester, D,L- $\alpha$-Glycerol phosphate and Glucose-L-phosphate). Briefly, $10 \mathrm{~g}$ of fresh soil was added to $90 \mathrm{ml}$ of sterilized $\mathrm{NaCl}(0.85 \%)$ solution and shaken at $200 \mathrm{rpm} \mathrm{min}^{-1}$ for $30 \mathrm{~min}$. Ten-fold serial dilutions were prepared, and each well of the Biolog Eco-plates was inoculated with $150 \mu \mathrm{L}$ of the $10^{-2}$ suspension. The plates were incubated at $30{ }^{\circ} \mathrm{C}$ for 10 days, and the

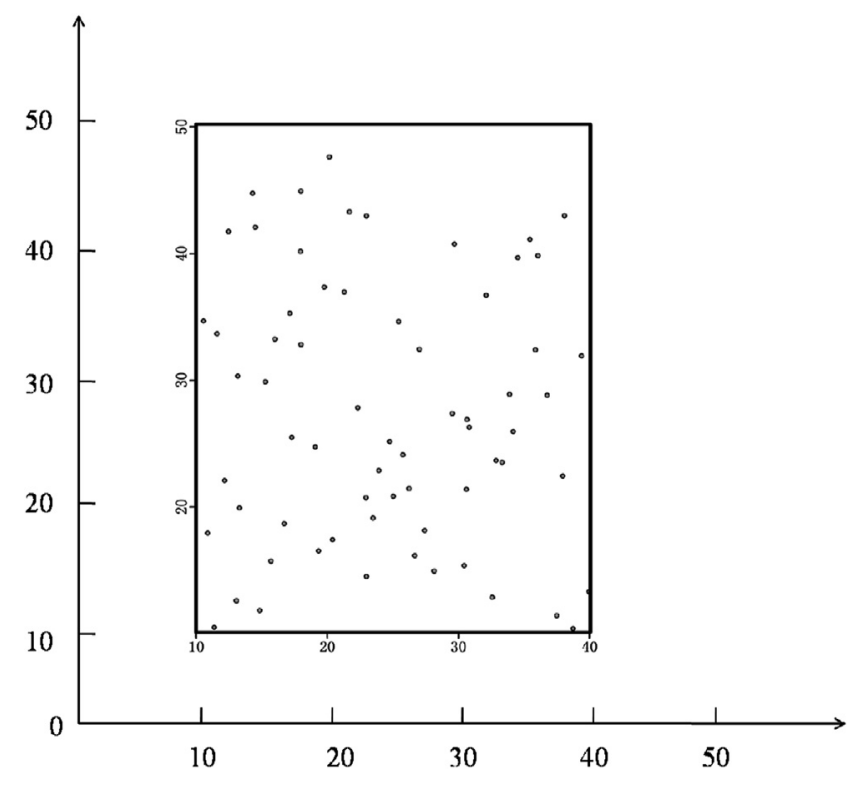

Fig. 1. The soil sampling scheme. 
color development was read as absorbance every $24 \mathrm{~h}$ with an automated plate reader (VMAX, Molecular Devices, Crawley, UK) at a wavelength of $590 \mathrm{~nm}$.

\subsection{Soil chemical analyses}

The air-dried samples were first passed through a $2 \mathrm{~mm}$ sieve, then ball-milled and analyzed for soil organic carbon (SOC) and total nitrogen (TN) by dry combustion using an EA1108 CHN elemental analyzer (Fisons Instruments, Germany).

Dissolved organic C and N (DOC and DON) were measured according to the method recommended by Jones and Willett [40]. The field-moist soil samples (equivalent to $15 \mathrm{~g}$ oven-dried soil) were extracted with $60 \mathrm{ml}$ of $0.05 \mathrm{~mol} \mathrm{~L}^{-1} \mathrm{~K}_{2} \mathrm{SO}_{4}$ (soil to solution ratio 1:4) for $1 \mathrm{~h}$. The extract was then passed through a $0.45-\mu \mathrm{m}$ membrane filter and analyzed for DOC and total dissolved $\mathrm{N}$ using a Multi 3100 N/C TOC analyzer (Analytik Jena, Germany). Subsamples were analyzed for $\mathrm{NH}_{4}^{+}$and $\mathrm{NO}_{3}^{-}$using an autoanalyzer (TRAACS2000, BRAN + LUEBBE, Germany); DON was calculated as the difference between the total dissolved $\mathrm{N}$ and the combined $\mathrm{NH}_{4}^{+}$and $\mathrm{NO}_{3}^{-}$.

Particulate organic C and N (POC and PON) were determined using the method described by Cambardella and Elliott [41]. Twenty grams of air-dried soil $(<2 \mathrm{~mm})$ were dispersed in $100 \mathrm{ml}$ of sodium hexametaphosphate $\left(\left(\mathrm{NaPO}_{3}\right)_{6}\right)\left(5 \mathrm{~g} \mathrm{~L}^{-1}\right)$. The mixture was shaken by hand during the first $10 \mathrm{~min}$, then on a reciprocating shaker $\left(180 \mathrm{rpm} \mathrm{min}{ }^{-1}\right.$ ) for $18 \mathrm{~h}$. The soil suspension was poured over a $53 \mu \mathrm{m}$ sieve using a flow of distilled water. All material remaining on the sieve, defined as the particulate organic pool, was washed into a dry dish, oven-dried at $65{ }^{\circ} \mathrm{C}$, weighed, ball-milled and analyzed for $\mathrm{C}$ and $\mathrm{N}$ by dry combustion using an EA1108 CHN elemental analyzer (Fisons Instruments, Germany).

\subsection{Calculations and statistical analyses}

The $72 \mathrm{~h}$ absorbance values were used to calculate the average well color development (AWCD), which indicates the microbial metabolic activity, as follows [35]:

$\mathrm{AWCD}=\sum(\mathrm{Ci}-\mathrm{r}) / 31$

where $\mathrm{Ci}$ is the absorbance from each well and $\mathrm{r}$ is the comparable absorbance of the control well. Negative $(\mathrm{Ci}-\mathrm{r})$ values were set to zero.

The $72 \mathrm{~h}$ absorbance values were also analyzed to calculate catabolic diversity (Shannon-Weiner diversity index, $\mathrm{H}^{\prime}$ ) [36]. The microbial community functional diversity indicated by the Shannon-Weiner diversity index was calculated as follows:

$\mathrm{H}^{\prime}=\sum$ pi lnpi

where $\mathrm{pi}=(\mathrm{Ci}-\mathrm{r}) / \sum(\mathrm{Ci}-\mathrm{r})$.

Principal component analysis (PCA) of the $72 \mathrm{~h}$ Biolog data (the relative absorbance) was used to identify the most discriminatory effects on the $C$ source metabolic functions. Redundancy analysis (RDA) was used to quantify the effects of soil environmental data on the variation of soil microbial functional diversity. PCA and RDA analyses were conducted using Canoco for Windows 4.5. Statistical tests using Canoco were run using the Monte Carlo permutation procedure.

Geostatistical analyses were used to visualize the spatial distribution of the soil microbial data. Semivariograms were used to determine the relatedness of soil microbial data with increasing distance between samples. Each variogram provides information of nugget variance $\left(C_{0}\right)$, structural variance $(C)$, sill $\left(C+C_{0}\right)$, range $(R)$ and the proportion of structural variance $\left(C / C+C_{0}\right)$. The nugget refers to the undetectable experimental error and field variation within the minimum sampling space, while sill represents total spatial variation [42]. The proportion of structural variance $(\mathrm{C} /$ $\mathrm{C}+\mathrm{C}_{0}$ ) varies from 0 to 1 , with 0 indicating no measurable spatial structure and 1 indicating that all variance is caused by spatial structure $[7,43]$. The range indicates the distance at which data are no longer spatially autocorrelated [7,43]. The experimental variogram can be fit with spherical, Gaussian, exponential or linear models [44]. The resulting $r^{2}$ values indicate how well the model semivariogram fits the experimental semivariogram. Finally, spatial maps were generated using standard kriging based on the best-fit model semivariograms (spatial interpolation). Semivariograms and kriging were performed with the geostatistical software GS+ version 9.

\section{Results}

\subsection{Spatial variability of soil microbial metabolic functional diversity}

Across the plot, metabolic activity (indicated as AWCD) varied between $0.51-1.57$ at $0-10 \mathrm{~cm}$ and $0.51-0.54$ at $10-20 \mathrm{~cm}$ soil depth (Table 1). The average value for the Shannon-Weiner diversity index was 2.59 in the upper soil layer, whereas it was 2.65 in the lower soil layer. Both the metabolic activity and diversity index showed higher variability (CV \%) in the upper 0-10 cm than in the lower $10-20 \mathrm{~cm}$ soil layer. Principal component analyses (PCA) showed that PC1 and PC2 accounted for 58.7 and $11.4 \%$ of the total variance at the $0-10 \mathrm{~cm}$ soil depth, while 48.6 and $10.8 \%$ in 10-20 cm soil depth, respectively (Fig. 2). In both soil layers, PC1 was mainly driven by strong positive correlations with the availability of most of the different $C$ substrates including carbohydrates, carboxylic acids and amino acids $\left(R^{2}>0.6\right.$, Fig. 2$)$.

\subsection{Spatial variability of soil organic matter and labile $C$ and $N$ fractions}

The SOC content varied between $54-184 \mathrm{~g} \mathrm{~kg}^{-1}$ in the upper layer and $14-161 \mathrm{~g} \mathrm{~kg}^{-1}$ in the lower soil layer with a CV of $30.9 \%$ and $55.3 \%$, respectively (Fig. 3 ). The pattern of variability for the TN was similar to the SOC, but the concentration was 14 times lower than the SOC (Fig. 3). The average values for the DOC were 198 and $109 \mathrm{mg} \mathrm{C} \mathrm{kg}^{-1}$ in the $0-10$ and $10-20 \mathrm{~cm}$ soil layers, while the DON averaged 23.5 and $13.4 \mathrm{mg} \mathrm{N} \mathrm{kg}^{-1}$ in $0-10$ and $10-20 \mathrm{~cm}$ soil layers, respectively. The POC concentration accounted for $4.48 \%$ of the SOC in upper soil layer, whereas it accounted for $4.05 \%$ in the lower soil layer (Fig. 3). At the same time, average PON only accounted for $2.04 \%$ of TN averaged across two soil layers with concentrations was $0.17 \mathrm{~g} \mathrm{~kg}^{-1}$ in upper and $0.08 \mathrm{~g} \mathrm{~kg}^{-1}$ in lower soil layer (Fig. 3).

Table 1

Descriptive statistics for metabolic function of soil microbial communities in two soil depths.

\begin{tabular}{lrllllc}
\hline & & Mean & Min. & Max. & SE & CV\% \\
\hline Metabolic activity $\left(\mathrm{AWCD}_{72 \mathrm{~h}}\right)$ & $0-10 \mathrm{~cm}$ & 1.00 & 0.51 & 1.57 & 0.03 & 28.8 \\
& $10-20 \mathrm{~cm}$ & 0.53 & 0.51 & 0.54 & 0.001 & 1.18 \\
Metabolic diversity $\left(\mathrm{H}^{\prime}\right)$ & $0-10 \mathrm{~cm}$ & 2.59 & 2.19 & 3.35 & 0.036 & 11.7 \\
& $10-20 \mathrm{~cm}$ & 2.65 & 2.63 & 2.69 & 0.002 & 0.60 \\
\hline
\end{tabular}

SE: standard error, CV: coefficient of variations. 

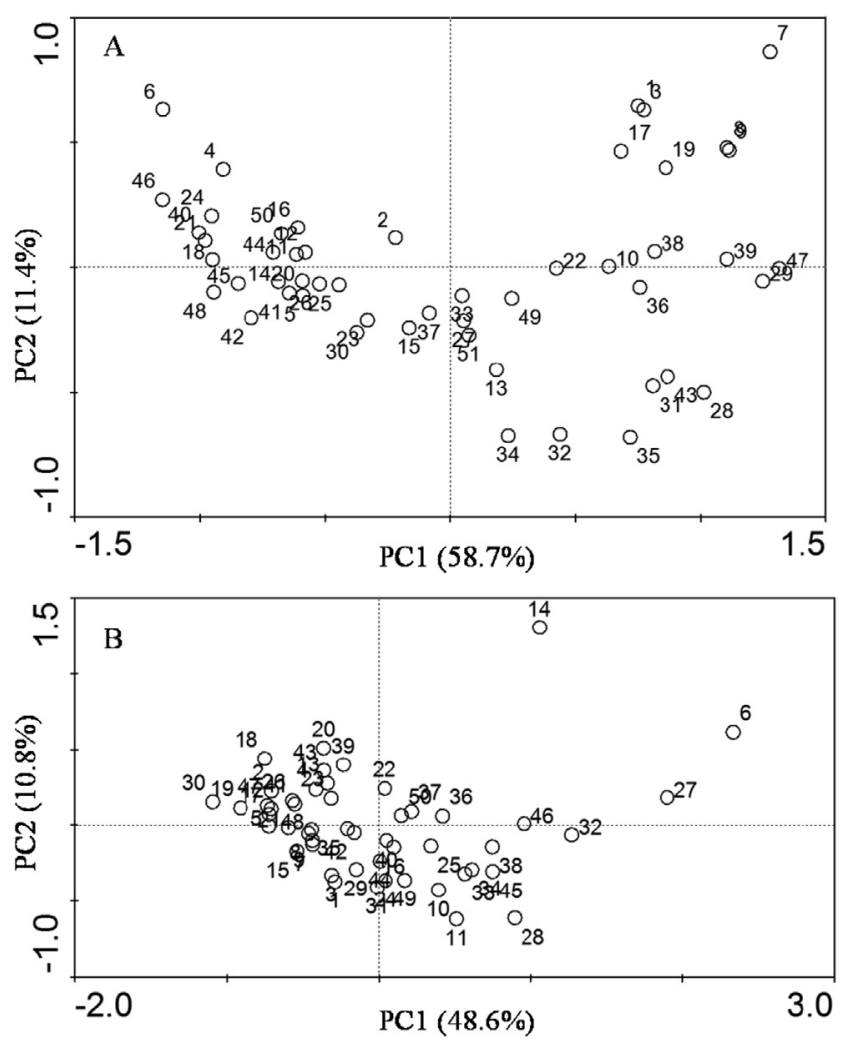

Fig. 2. Principal component analyses of the substrate utilization patterns using Biolog assays in the $0-10 \mathrm{~cm}(\mathrm{~A})$ and $10-20 \mathrm{~cm}$ (B) soil depths. The numbers in the figure means the different sampling points.

\subsection{Spatial structure for soil microbial metabolic functional diversity}

Results obtained from the variograms and fitted models suggested that the soil microbial functional diversity was spatially structured (Table 2). The optimal theoretical models for metabolic activity (AWCD) and functional diversity (Shannon-Weaver) were exponential and spherical, respectively. The metabolic activity showed moderate spatial dependence with nuggets representing $34.5-50 \%$ of the total variance in both soil layers. While the corresponding nugget to sill ratio for functional diversity was $<0.25$, suggesting a stronger spatial dependence. The spatial dependence ranged from 11.3 to $51.0 \mathrm{~m}$ for metabolic activity and 8.82 to $28.7 \mathrm{~m}$ for functional diversity (Table 2). In the case of metabolic activity the range was greater in the $0-10 \mathrm{~cm}$ soil layer while the range for functional diversity for was greater in the $10-20 \mathrm{~cm}$ layer. The kriged maps highlighted the patches of higher metabolic activity and functional diversity (Fig. 4). From these maps it is apparent that hotspots for high metabolic activity were not necessarily related to areas of high functional diversity, particularly in the upper soil layer (Fig. 4). The maps also further indicated the generally lower spatial variability in the lower soil layer compared to the upper layer.

\subsection{Effect of soil organic matter and labile $C$ and $N$ fractions on soil microbial metabolic functional diversity}

The correlations between soil microbial metabolic functional diversity and SOM fractions data are shown in Fig. 5. The RDA plots indicated that PC1 and PC2 accounted for $21.3 \%$ and $2.10 \%$ of the total variance in the upper soil layer. All the SOM fractions variables combined explained $27 \%$ of the variance in the soil microbial functional diversity (Monte Carlo permutation test) in the $0-10 \mathrm{~cm}$ soil layer. The variables explaining the largest statistically significantly amount of variation were the DOC (17\%), and then followed by the SOC ( $9 \%$ ) and PON (2\%).

PC1 and PC2 accounted for 10.3 and $1.80 \%$ of the total variance in the $10-20 \mathrm{~cm}$ soil layer, respectively. The SOM fractions that were most strongly correlated with the axis included the DOC $(p=0.008)$ and DON $(p=0.022)$. The combined SOM fractions explained $15 \%$ of the variance in soil microbial functional diversity (Monte Carlo permutation test). The variables explaining the largest amount of variation were the DOC, DON and PON, which together accounted for $13 \%$ of the variance in soil microbial functional diversity.

\section{Discussion}

Soil microorganisms are actively involved in soil biochemical processes, including organic matter decomposition, nutrient mineralization and cycling. Appreciating patterns of microbial functional diversity and the factors that determine these patterns could lead to more accurate predictions of microbial properties and functions within an ecosystem [5,6]. In this study, we investigated whether spatial patterns of microbial functional diversity was related to total SOM and labile $\mathrm{C}$ and $\mathrm{N}$ fractions across two soil depths in a diverse temperate forest. Community level physiological profiles (CLPP) obtained by Biolog Eco-plate were used to indicate the soil microbial functional diversity in the current study. However, caution is required in interpreting the results due to the arbitrary concentrations and selection of carbon sources used in the plates which do not reflect the natural environment [39]. Despite the disadvantages, this method has been widely used in determining soil microbial community functional diversity under various conditions and provides a ready means to compare microbial activity across space and under a range of ecosystem types [36-38].

As expected, the soil microbial metabolic functional diversity showed high variability and spatial autocorrelation at scales of 8-51 m (Table 1, Fig. 2, Table 2 and Fig. 4). The nugget to sill ratio was 0.42 for metabolic activity, whereas it was $<0.25$ for metabolic functional diversity. These results suggest that the microbial metabolic activity, especially diversity showed strong spatial dependence. The higher coefficient of variance and higher sill value in the upper soil layer indicates that soil microbial metabolic activity and functional diversity at the soil surface were strongly affected by environmental variability. At the same time, conditions in the $10-20 \mathrm{~cm}$ layer were likely more stable which may be responsible for the roughly equal estimates of diversity among the two layers despite greater metabolic activity being measured from the upper layer soils (Table 1 ).

The availability of different organic resources is regarded as one of the most important environmental factors in influencing soil microbial biomass, activity and structure [45]. Previous studies have reported the effect of leaf litter, total SOC and nutrient availability on microbial diversity [46-48]. Others have also found that decreases in SOC reserves following land-use change broadly reduced the metabolic diversity of soil microbial communities [28]. In this study, the combined SOM fractions explained $27 \%$ of the variance in soil microbial metabolic functional diversity in the upper soil layer while 15\% in lower layer (Fig. 5). This supported our hypothesis that SOM resource plays an important role in determining soil microbial metabolic functional diversity. However, the unexplained variation was also high, which may be caused by additionally environmental factors including plant species, soil $\mathrm{pH}$, soil moisture and other soil characteristics [10-13]. Additionally, a number of studies have documented that changes of soil microbial community and activities could be regulated by $\mathrm{C}$ and $\mathrm{N}$ availability 

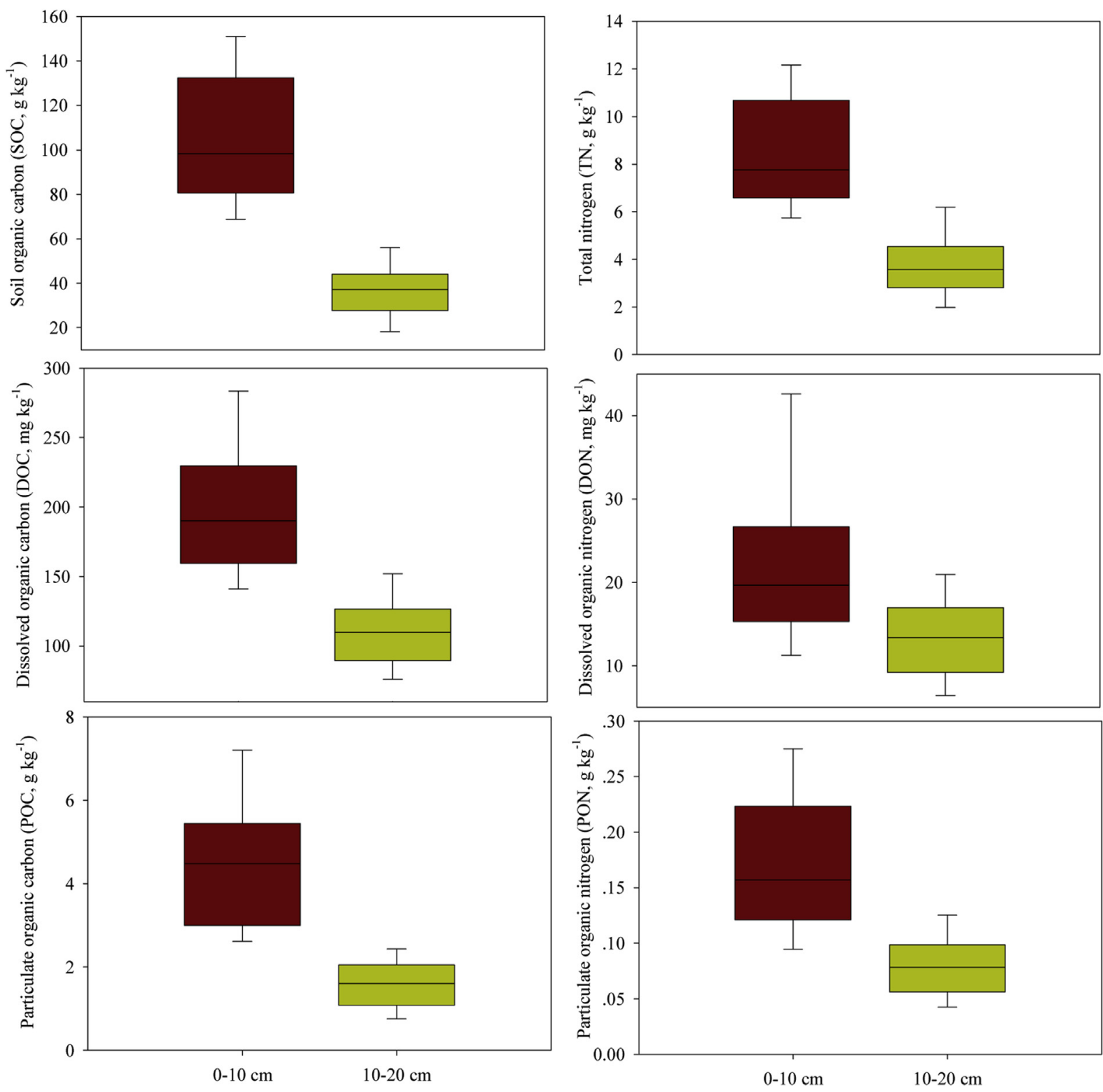

Fig. 3. Contents of soil organic matter, dissolved organic matter and particulate organic matter in the $0-10 \mathrm{~cm}$ and $10-20 \mathrm{~cm}$ soil depths.

through certain SOM pools [25,27,49]. We also observed high spatial variability of SOM fractions (Fig. 3), this may result in changes of soil community structure at different spatial scales. Therefore, we can not rule out variation in different microbial community structure as a potential cause for the differences in substrate utilization patterns. This also perhaps helps to explain the lower contribution of SOM to the variance of soil microbial metabolic functional diversity in the lower soil layer. As corresponding to the findings that the distribution of microbial community was largely attributed to the decline of SOC content with increasing soil depth [50].

In addition to total SOM, separate fractions of labile SOM can also be important in determining microbial metabolic function and diversity. Among all the SOM fractions, the DOC accounted for the largest amount of variation microbial activity in both soil layers, especially it accounted for $17 \%$ variation in upper soil layer (Fig. 5). This finding agrees with previous studies showing that DOC is the primary energy source for microorganisms and affects their activity in the soil [25,27]. Churchland et al. [17] also reported that even in disturbed sites, DOC was the main source of $C$ that influenced the composition of the microbial community and soil respiration rates up to ten meters from a forested to clear-cut site. Another study found that the addition of $\mathrm{N}$ changed the amount and biodegradability of soil DOC through stimulating microbial metabolic activity and preferentially utilizing organic acids based on Biolog analyses [51]. The previous studies and the results of this study indicated that changes in the soil microbial community, activity and functional diversity may be regulated by $\mathrm{C}$ and $\mathrm{N}$ availability through labile SOM pools. Litterfall, root turnover and exudation were interpreted as providing significant contributions to the DOC production in the forest soil, as it consisted mainly of simple sugars and non humic-bound polysaccharides [52,53]. Presumably, the highly heterogeneous nature of aboveground vegetation composition [30], belowground root biomass [31] and rhizosphere resources such as root exudation [16] in forest ecosystems should induce high variability of DOC in the forest soils as was observed in this study 
Table 2

Parameters of the best-fitted semi-variogram for metabolic function of soil microbial communities in two soil depths.

\begin{tabular}{|c|c|c|c|c|c|c|c|}
\hline & & Model & Nugget $\left(C_{0}\right)$ & Sill $\left(C+C_{0}\right)$ & Range & $\mathrm{C} / \mathrm{C}+\mathrm{C}_{0}$ & $R^{2}$ \\
\hline \multirow[t]{2}{*}{ Metabolic activity $\left(\mathrm{AWCD}_{72 \mathrm{~h}}\right)$} & $0-10 \mathrm{~cm}$ & exponential & 0.067 & 0.135 & 51.00 & 0.500 & 0.219 \\
\hline & $10-20 \mathrm{~cm}$ & exponential & 0.00002 & 0.00006 & 11.27 & 0.655 & 0.808 \\
\hline \multirow[t]{2}{*}{ Metabolic diversity $\left(\mathrm{H}^{\prime}\right)$} & $0-10 \mathrm{~cm}$ & spherical & 0.0002 & 0.072 & 8.82 & 0.997 & 0.950 \\
\hline & $10-20 \mathrm{~cm}$ & spherical & 0 & 0.00040 & 28.70 & 0.997 & 0.973 \\
\hline
\end{tabular}

Units for nugget, sill, and range are in meters.

\section{$0-10 \mathrm{~cm}$}
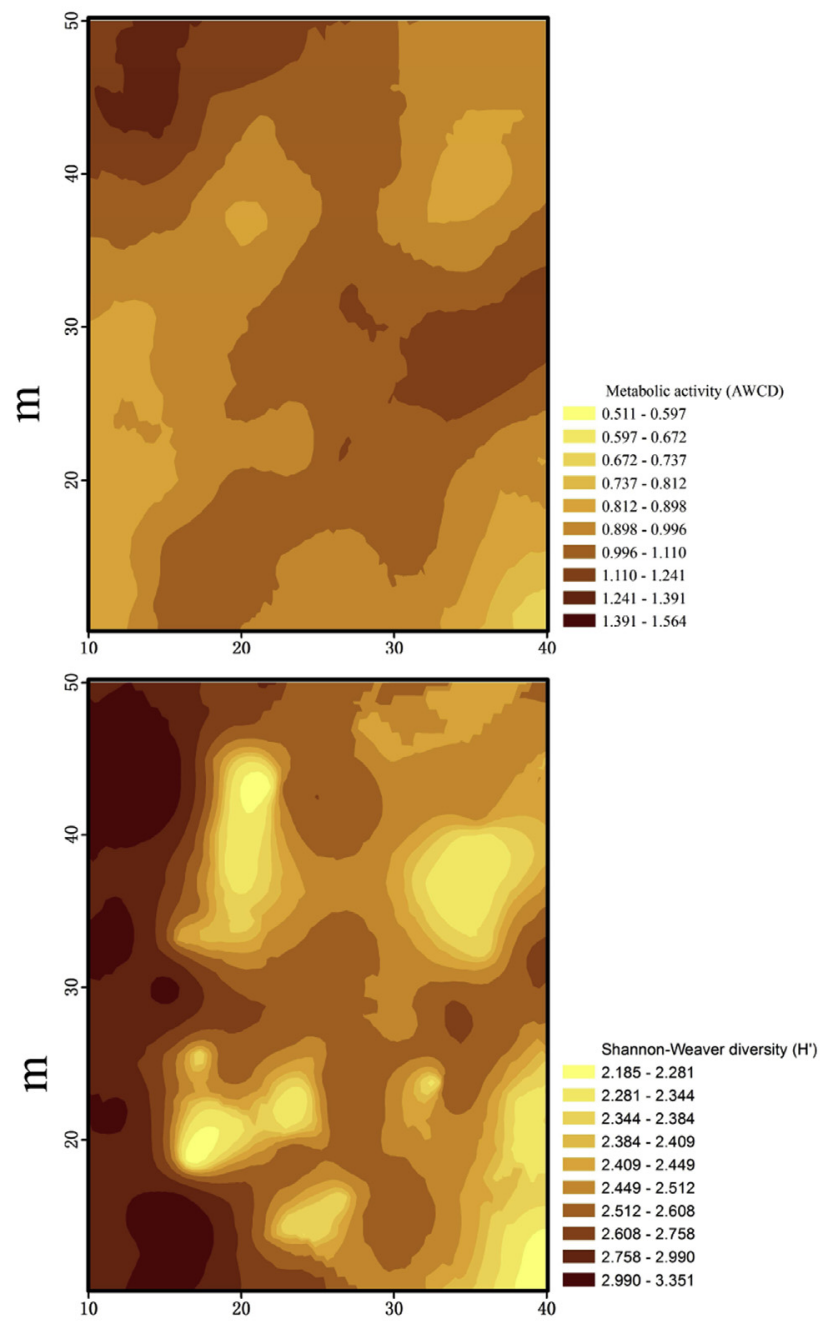

$10-20 \mathrm{~cm}$
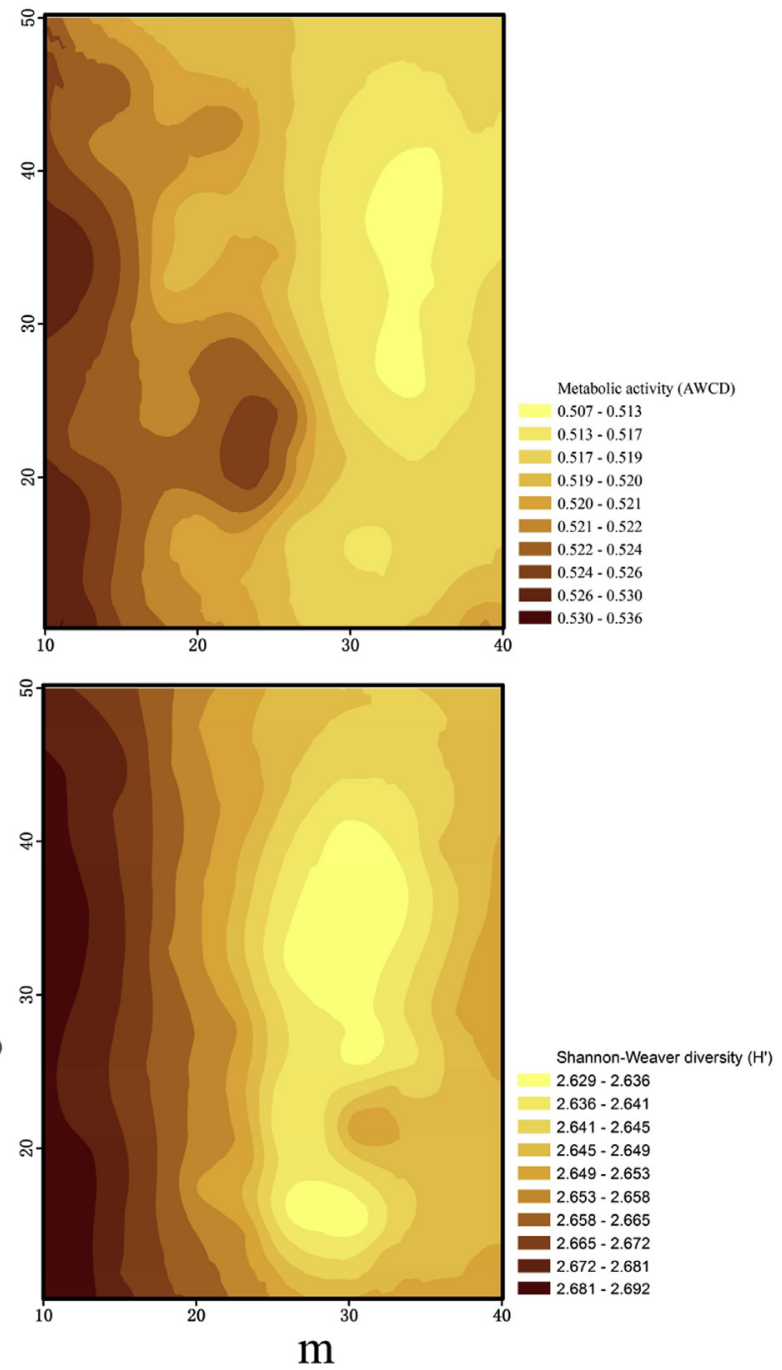

Fig. 4. Kriging maps for metabolic activity (top) and Shannon-Weaver diversity (bottom) in the $0-10 \mathrm{~cm}$ (the left column) and $10-20 \mathrm{~cm}$ (the right column) soil depths.

(Fig. 3). Finally, the labile plant C entering the DOC fraction through root and mycorrhizal turnover and root exudation could exert a large influence on soil microbial metabolic functional diversity as was found in this study. However, as mentioned above, the selection of $\mathrm{C}$ sources used in the Eco-plates does not fully represent the natural environment, e.g. due to the lack of more recalcitrant compounds, therefore, the comprehensively description of the influence of soil organic matter fractions in explaining the microbial functional diversity remains to be determined in future.

\section{Conclusions}

This study showed that the soil microbial metabolic functional diversity had high variability and strong spatial autocorrelation at the sub-plot level. The findings also demonstrated that SOM fractions, particularly the labile DOC fraction, can explain a significant portion of the variation of soil microbial functional diversity, especially in the soil surface. The importance of the SOM fractions in structuring soil microbial functional diversity provides insight into the close relationship between soil microorganisms and SOM, which may help us to better understand ecological processes 

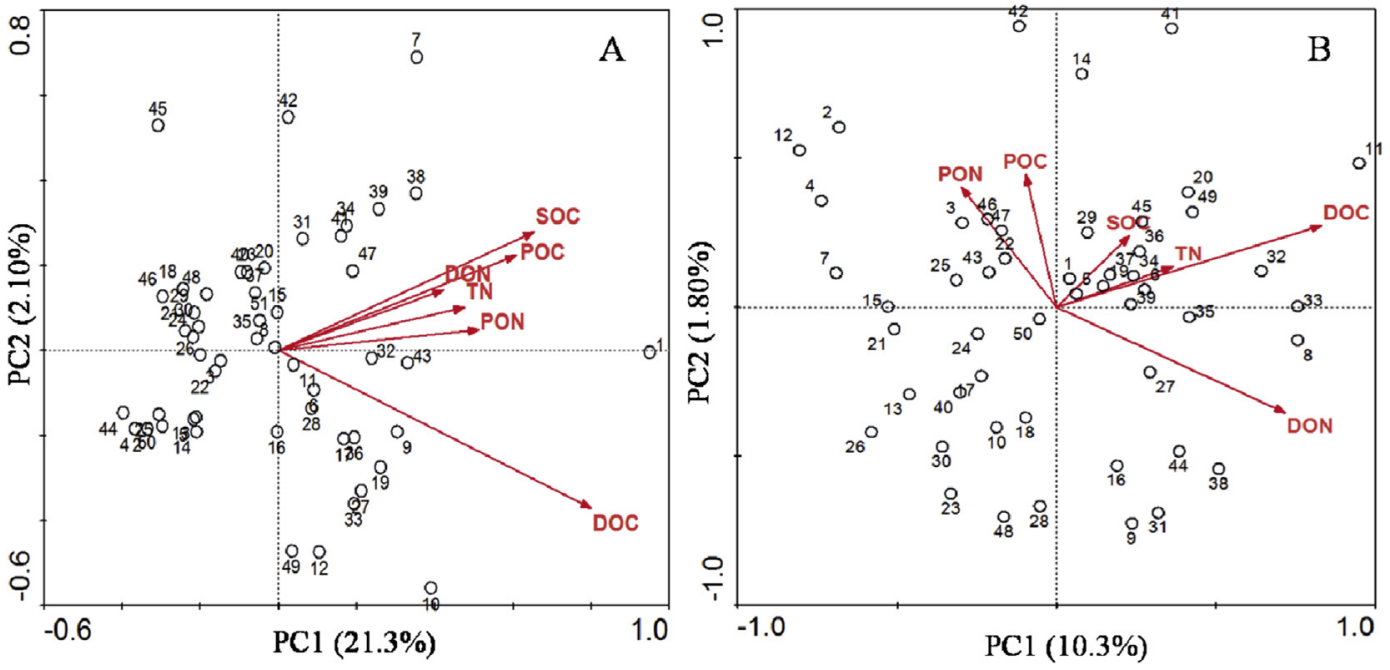

Fig. 5. Redundancy analysis (RDA) of the substrate utilization patterns constrained by soil SOM fractions in the $0-10 \mathrm{~cm}(\mathrm{~A})$ and $10-20 \mathrm{~cm}$ (B) soil depths.

including $\mathrm{C}$ cycling in forest ecosystems. It remains necessary to quantify the relative importance of other environmental factors including plant species, soil $\mathrm{pH}$ and soil moisture as well as other biological processes including soil microbial community in structuring soil microbial functional diversity in future.

\section{Acknowledgments}

We thank National Natural Science Foundation of China (Grant Nos. 31290221 and 31400460), Major Program of National Natural Science Foundation of China (Grant No. 31420103917) and the Open Fund of Key Laboratory of China Academy of Science (Grant No. 08R8B161PA) for generous financial support. The contribution of EB was supported by Russian Scientific Foundation (Grant No. 14-1400625). We also thank the two anonymous reviewers for their helpful comments that helped us to greatly improve the manuscript.

\section{References}

[1] T.C. Balser, M.K. Firestone, Linking microbial community composition and soi processes in a California annual grassland and mixed-conifer forest, Biogeochemistry 73 (2) (2005) 395-415.

[2] J. Six, S.D. Frey, R.K. Thiet, K.M. Batten, Bacterial and fungal contributions to carbon sequestration in agroecosystems, Soil Sci. Soc. Am. J. 70 (2) (2006) 555-569.

[3] K.E. Clemmensen, A. Bahr, O. Ovaskainen, A. Dahlberg, A. Ekblad, H. Wallander, J. Stenlid, R.D. Finlay, D.A. Wardle, B.D. Lindahl, Roots and associated fungi drive long-term carbon sequestration in boreal forest, Science 339 (6127) (2013) 1615-1618.

[4] F.A. Rutigliano, R. D'Ascoli, A.V. De Santo, Soil microbial metabolism and nutrient status in a Mediterranean area as affected by plant cover, Soil Biol. Biochem. 36 (11) (2004) 1719-1729.

[5] C.H. Ettema, D.A. Wardle, Spatial soil ecology, Trends Ecol. Evol. 17 (4) (2002) $177-183$

[6] J.L. Green, A.J. Holmes, M. Westoby, I. Oliver, D. Briscoe, M. Dangerfield M. Gillings, A.J. Beattie, Spatial scaling of microbial eukaryote diversity, Nature 432 (7018) (2004) 747-750.

[7] S.J. Morris, Spatial distribution of fungal and bacterial biomass in southern Ohio hardwood forest soils: fine scale variability and microscale patterns, Soil Biol. Biochem. 31 (10) (1999) 1375-1386.

[8] P. Baldrian, V. Merhautova, T. Cajthaml, M. Petrankova, J. Snajdr, Small-scale distribution of extracellular enzymes, fungal, and bacterial biomass in Quercus petraea forest topsoil, Biol. Fertil. Soils 46 (7) (2010) 717-726.

[9] J. Snajdr, V. Valaskova, V. Merhautova, J. Herinkova, T. Cajthaml, P. Baldrian, Spatial variability of enzyme activities and microbial biomass in the upper layers of Quercus petraea forest soil, Soil Biol. Biochem. 40 (9) (2008) 2068-2075.

[10] M.P. Waldrop, D.R. Zak, C.B. Blackwood, C.D. Curtis, D. Tilman, Resource availability controls fungal diversity across a plant diversity gradient, Ecol.
Lett. 9 (10) (2006) 1127-1135.

[11] N. Fierer, R.B. Jackson, The diversity and biogeography of soil bacterial communities, Proc. Natl. Acad. Sci. U. S. A. 103 (3) (2006) 626-631.

[12] M. Viketoft, Determinants of small-scale spatial patterns: importance of space, plants and abiotics for soil nematodes, Soil Biol. Biochem. 62 (2013) 92-98.

[13] A. Stein, K. Gerstner, H. Kreft, Environmental heterogeneity as a universal driver of species richness across taxa, biomes and spatial scales, Ecol. Lett. 17 (7) (2014) 866-880

[14] E.M. Spehn, J. Joshi, B. Schmid, J. Alphei, C. Korner, Plant diversity effects on soil heterotrophic activity in experimental grassland ecosystems, Plant Soil 224 (2) (2000) 217-230.

[15] E. Katsalirou, S.P. Deng, D.L. Nofziger, A. Gerakis, S.D. Fuhlendorf, Spatial structure of microbial biomass and activity in prairie soil ecosystems, Eur. J. Soil Biol. 46 (3-4) (2010) 181-189.

[16] A.C.S. McIntosh, S.E. Macdonald, S.A. Quideau, Linkages between the forest floor microbial community and resource heterogeneity within mature lodgepole pine forests, Soil Biol. Biochem. 63 (2013) 61-72.

[17] C. Churchland, S.J. Grayston, P. Bengtson, Spatial variability of soil fungal and bacterial abundance: consequences for carbon turnover along a transition from a forested to clear-cut site, Soil Biol. Biochem. 63 (2013) 5-13.

[18] K. Ritz, W. McNicol, N. Nunan, S. Grayston, P. Millard, D. Atkinson, A. Gollotte, D. Habeshaw, B. Boag, C.D. Clegg, B.S. Griffiths, R.E. Wheatley, L.A. Glover, A.E. McCaig, J.I. Prosser, Spatial structure in soil chemical and microbiological properties in an upland grassland, FEMS Microbiol. Ecol. 49 (2) (2004) $191-205$.

[19] Z.F. Liu, B.J. Fu, X.X. Zheng, G.H. Liu, Plant biomass, soil water content and soil $\mathrm{N}$ : P ratio regulating soil microbial functional diversity in a temperate steppe: a regional scale study, Soil Biol. Biochem. 42 (3) (2010) 445-450.

[20] G.B. De Deyn, W.H. Van der Putten, Linking aboveground and belowground diversity, Trends Ecol. Evol. 20 (11) (2005) 625-633.

[21] F.J. Stevenson, Humus Chemistry: Genesis, Composition, Reactions, John Wiley \& Sons, New York, 1994, p. 496.

[22] R.J. Haynes, Labile organic matter fractions as central components of the quality of agricultural soils: an overview, Adv. Agron. 85 (2005) 221-268.

[23] M. von Lüetzow, I. Koegel-Knabner, K. Ekschmitt, H. Flessa, G. Guggenberger, E. Matzner, B. Marschner, SOM fractionation methods: relevance to functional pools and to stabilization mechanisms, Soil Biol. Biochem. 39 (9) (2007) 2183-2207.

[24] B. Marschner, K. Kalbitz, Controls of bioavailability and biodegradability of dissolved organic matter in soils, Geoderma 113 (2003) 211-235.

[25] W.R. Cookson, D.A. Abaye, P. Marschner, D.V. Murphy, E.A. Stockdale, K.W.T. Goulding, The contribution of soil organic matter fractions to carbon and nitrogen mineralization and microbial community size and structure, Soil Biol. Biochem. 37 (9) (2005) 1726-1737.

[26] Z.O. Huang, Z.H. Xu, C.R. Chen, Effect of mulching on labile soil organic matter pools, microbial community functional diversity and nitrogen transformations in two hardwood plantations of subtropical Australia, Appl. Soil Ecol. 40 (2) (2008) 229-239.

[27] J. Tian, M.F. Fan, J.H. Guo, P. Marschner, X.L. Li, Y. Kuzyakov, Effects of land use intensity on dissolved organic carbon properties and microbial community structure, Eur. J. Soil Biol. 52 (2012) 67-72.

[28] B.P. Degens, L.A. Schipper, G.P. Sparling, M. Vojvodic-Vukovic, Decreases in organic $C$ reserves in soils can reduce the catabolic diversity of soil microbial communities, Soil Biol. Biochem. 32 (2) (2000) 189-196.

[29] W.V. Sobczak, L.O. Hedin, M.J. Klug, Relationships between bacterial productivity and organic carbon at a soil-stream interface, Hydrobiologia 386 (1998) 
$45-53$.

[30] P. Saetre, Spatial patterns of ground vegetation, soil microbial biomass and activity in a mixed spruce-birch stand, Ecography 22 (2) (1999) 183-192.

[31] Z.H. Sun, C.C. Mu, L. Sun, The estimate of fine root biomass in upper soil layer of Larix olgensis plantation by geostatistics method (in Chinese), Acta Phytoecol. Sin. 30 (5) (2006) 771-779.

[32] Y. Liao, M.L. McCormack, D. Guo, H. Wang, J. Wu, J. Tu, W. Liu, Relation of fine root distribution to soil $\mathrm{C}$ in Cunninghamia lanceolata forest in subtropical China, Plant Soil 381 (2014) 225-234.

[33] J.H. Zhang, S.J. Han, G.R. Yu, Seasonal variation in carbon dioxide exchange over a 200-year-old Chinese broad-leaved Korean pine mixed forest, Agric. For. Meteorol. 137 (3-4) (2006) 150-165.

[34] C.G. Xu, H.S. He, Y.M. Hu, Y. Chang, X.Z. Li, R.C. Bu, Latin hypercube sampling and geostatistical modeling of spatial uncertainty in a spatially explicit forest landscape model simulation, Ecol. Model. 185 (2-4) (2005) 255-269.

[35] J.L. Garland, A.L. Mills, Classification and characterization of heterotrophic microbial communities on the basis of patterns of community-level sole carbon-source utilization, Appl. Environ. Microbiol. 57 (1991) 2351-2359.

[36] J.C. Zak, M.R. Willig, D.L. Moorhead, H.G. Wildman, Functional diversity of microbial communities - a quantitative approach, Soil Biol. Biochem. 26 (9) (1994) 1101-1108.

[37] H. Zheng, Z.Y. Ouyang, X.K. Wang, Z.G. Fang, T.Q. Zhao, H. Miao, Effects of regenerating forest cover on soil microbial communities: a case study in hilly red soil region, southern China, For. Ecol. Manag. 217 (2005) 244-254.

[38] J.P. Wu, Z.F. Liu, X.L. Wang, Y.X. Sun, L.X. Zhou, Y.B. Lin, S.L. Fu, Effects of understory removal and tree girdling on soil microbial community composition and litter decomposition in two Eucalyptus plantations in South China, Funct. Ecol. 25 (4) (2011) 921-931.

[39] J. Preston-Mafham, L. Boddy, P.F. Randerson, Analysis of microbial community functional diversity using sole-carbon-source utilization profiles -a critique, FEMS Microbiol. Ecol. 42 (2002) 1-14.

[40] D.L. Jones, V.B. Willett, Experimental evaluation of methods to quantify dissolved organic nitrogen (DON) and dissolved organic carbon (DOC) in soil, Soil Biol. Biochem. 38 (5) (2006) 991-999.

[41] C.A. Cambardella, E.T. Elliott, Particulate soil organic matter changes across a grassland cultivation sequence, Soil Sci. Soc. Am. J. 56 (3) (1992) 777-783.
[42] F. Shahbazi, N. Aliasgharzad, S.A. Ebrahimzad, N. Najafi, Geostatistical analysis for predicting soil biological maps under different scenarios of land use, Eur. J. Soil Biol. 55 (2013) 20-27.

[43] B.J. Pickles, D.R. Genney, J.M. Potts, J.J. Lennon, I.C. Anderson, I.J. Alexander Spatial and temporal ecology of Scots pine ectomycorrhizas, New Phytol. 186 (3) (2010) 755-768.

[44] I.F. Kuzyakov, V.A. Romanenkov, Y.V. Kuzyakov, Geostatistics in soil agrochemical studies, Eurasian Soil Sci. 34 (2001) 1011-1017.

[45] K. Jankowski, D.E. Schindler, M.C. Horner-Devine, Resource availability and spatial heterogeneity control bacterial community response to nutrient enrichment in lakes, Plos One 9 (1) (2014) e86991.

[46] J.Z. Zhou, B.C. Xia, D.S. Treves, L.Y. Wu, T.L. Marsh, R.V. O'Neill, A.V. Palumbo J.M. Tiedje, Spatial and resource factors influencing high microbial diversity in soil, Appl. Environ. Microbiol. 68 (1) (2002) 326-334.

[47] S. Hättenschwiler, A.V. Tiunov, S. Scheu, Biodiversity and litter decomposition in terrestrial ecosystems, Annu. Rev. Ecol. Syst. 36 (2005) 191-218.

[48] D.C. Housman, C.M. Yeager, B.J. Darby, R.L. Sanford, C.R. Kuske, D.A. Neher, J. Belnap, Heterogeneity of soil nutrients and subsurface biota in a dryland ecosystem, Soil Biol. Biochem. 39 (8) (2007) 2138-2149.

449] N. Fanin, S. Hättenschwiler, N. Fromin, Litter fingerprint on microbial biomass, activity, and community structure in the underlying soil, Plant Soil 379 (1-2) (2014) 79-91.

[50] N. Fierer, J.P. Schimel, P.A. Holden, Variations in microbial community composition through two soil depth profiles, Soil Biol. Biochem. 35 (1) (2003) $167-176$.

[51] H.J. Fang, S.L. Cheng, G.Y. Yu, M.J. Xu, Y.S. Wang, L.S. Li, X.S. Dang, L. Wang, Y.N. Li, Experimental nitrogen deposition alters the quantity and quality of soil dissolved organic carbon in an alpine meadow on the Qinghai-Tibetan Plateau, Appl. Soil Ecol. 81 (2014) 1-11.

[52] P. Casals, J. Romanya, J. Cortina, J. Fons, M. Bode, V.R. Vallejo, Nitrogen supply rate in Scots pine (Pinus sylvestris L.) forests of contrasting slope aspect, Plant Soil 168 (1995) 67-73.

[53] K. Kalbitz, S. Solinger, J.H. Park, B. Michalzik, E. Matzner, Controls on the dynamics of dissolved organic matter in soils: a review, Soil Sci. 165 (2000) 277-304. 